\title{
O desenvolvimento de políticas públicas e a influência do capital social na construção do desenvolvimento local sustentável
}

\section{Clarissa Maria Ramalho Sá Rocha1, Denise Pinto Gadelha², Sabrina Ribeiro de Almeida ${ }^{1}$}

1Programa de Pós-Graduação em Recursos Naturais (PPGRN). Universidade Federal de Campina Grande. Rua Aprígio Veloso, 882. Bairro Universitário. Campina Grande-PB. Brasil (CEP 58429-900). E-mail: clarissa_r2@yahoo.com.br.

${ }^{2}$ Departamento de Turismo e Hotelaria. Centro de Comunicação, Turismo e Artes. Universidade Federal da Paraíba. Campus I. João Pessoa-PB. Brasil (CEP 50851-900).

Resumo. Este trabalho tem como objetivo apresentar reflexões acerca do desenvolvimento local sustentável, incluindo as discussões e contribuições do capital social e das políticas públicas neste ambiente de mudança de paradigma. As políticas públicas no Brasil foram preponderantemente centralizadoras e paternalistas, voltadas ao atendimento dos interesses das pequenas elites. Deixando em segundo plano as políticas públicas voltadas para o social, causando o enfraquecimento na articulação e organização da sociedade civil para reivindicar seus direitos. Todavia, a partir dos anos 1970, influenciado por movimentos internacionais, as políticas no Brasil passam a pensar o social, o meio ambiente e a sustentabilidade. Neste ambiente, novos conceitos passam a ser estudados, como o de capital social e de desenvolvimento local sustentável. O capital social pode ser entendido como um estoque de valores que auxiliam os indivíduos ou um grupo no desenvolvimento e articulação das comunidades. Desta forma, para se construir um desenvolvimento local sustentável, tão importante para a sociedade moderna, que por meio da globalização tem concentrado renda e que ainda usa práticas degradadoras, é necessário aprofundar as discussões a cerca da sustentabilidade, do capital social e das políticas públicas, em um contexto local.

Palavras-chave: Desenvolvimento local; Sustentabilidade; Social capital.

\begin{abstract}
The development of public policies and the influence of social capital in the construction of sustainable local development. This work aims to present reflections on the sustainable local development, including the discussions and contributions of social capital and public policies in this paradigm shift environment. Public policies in Brazil were mainly centralized and paternalistic, aimed at meeting the interests of small elites. Background leaving public policies aimed at social, causing weakening in the articulation and organization of civil society to demand their rights. However from the 1970's, influenced by international movements the policies in Brazil are thinking about social, environment and sustainability. In this
\end{abstract}

Recebido: 25/10/2017

Aceito:

$28 / 12 / 2017$

Publicado:

31/12/2017

Acesso aberto Artigo completo

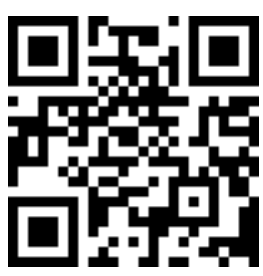

ORCID

(1) 0000-0003-3267-6198 Clarissa Maria Ramalho Sá Rocha

(D) 0000-0003-1103-265X Denise Pinto Gadelha (D) 0000-0002-9201-4172 Sabrina Ribeiro de Almeida 
environment, new concepts come to be studied, such as the concept of social capital and sustainable local development. Social capital can be understood as a stock of values that help individuals or a group in the development and articulation of communities. Thus, to build a sustainable local development, so important for modern society, which through globalization concentrates income and capital and still uses degrading practices, it is necessary to deepen the discussions about sustainability, social capital and political public, in a local context.

Keywords: Local development; Sustainability; Social capital.

\section{Introdução}

O presente artigo tem por objetivo apresentar reflexões acerca do desenvolvimento local em sua vertente sustentável incluindo, neste sentido, a formulação e o desenvolvimento das políticas públicas no Brasil, bem como os conceitos de capital social e as discussões sobre sustentabilidade.

Para ser sustentável o desenvolvimento precisa ser socialmente includente e ecologicamente equilibrado. O desenvolvimento sustentável, dentro dessa perspectiva, só conseguiria ser atingido mediante um conjunto de políticas eficientes que conseguisse garantir o aumento da renda, o acesso aos direitos sociais e reduzisse os impactos ao meio ambiente (Romeiro, 2012). Muitos podem considerar esse desenvolvimento utópico, porém mediante os desastres ambientais, causadas pela ação humana, e os limites de carga dos ecossistemas, essa se coloca como única alternativa possível para garantir 0 desenvolvimento e a vida, tal como vemos hoje, no planeta.

Todavia, os países não podem abrir mão de se desenvolver economicamente e gerar renda, pois é necessário garantir a dignidade da pessoa humana. Entretanto, é necessário perceber que desenvolvimento e crescimento são conceitos distintos. O crescimento econômico busca apenas o lucro e os ganhos de capital. Por outro lado, o desenvolvimento sustentável busca trabalhar sob o tripé econômico, social e ambiental. Desta forma, os países em desenvolvimento, no caso do Brasil, precisam buscar essa nova forma de desenvolvimento.

As políticas públicas e o papel do Estado, como lembra Romeiro (2012) devem ser eficiente no que concerne a regulação dos interesses dos diversos atores na tomada de decisão que, cause ou possa causar dano ambiental, além de fiscalizar e garantir a participação de todos os atores sociais envolvidos no processo de decisão. Porém não basta uma ação que aconteça após o dano, são necessárias políticas e leis que trabalhem sob o conceito da precaução, pois alguns danos ambientais não podem ser reparados.

Nesta mudança de paradigma de políticas públicas elitizadas para políticas participativas, se insere o conceito de capital social, que, segundo Novaes (2005), pode ser entendido como um conjunto de bens sociais, psicológicos, cognitivos e institucionais, que estão relacionados a um ator ou grupo, levando a uma melhor articulação em redes e a uma melhor organização e mobilização da sociedade civil, enfatizando a participação e o empoderamento (Fonseca e Bursztyn, 2009). No que se refere ao desenvolvimento local sustentável, o capital social é fator importante para que os atores da localidade consigam lutar por seus interesses e desenvolver as potencialidades da localidade.

Mediante a necessidade de construir um desenvolvimento local sustentável, especialmente no Brasil, os tópicos a seguir discutem a importância das políticas públicas na construção desse desenvolvimento, além de discutir os conceitos a cerca 
do capital social e do desenvolvimento local sustentável.

\section{As políticas públicas e o desenvolvimento local sustentável}

O desenvolvimento de políticas públicas no Brasil vem ganhando espaço na academia e no âmbito dos diversos governos que perpassaram pela União, da década de 1930 até o presente. É necessário pontuar que até o advento da Constituição de 1988 as políticas públicas estiveram voltadas para atender a interesses de grupos dominantes. Por este ângulo deve-se percebê-las como uma política intervencionista, verticalizada e centralizada, com bases no assistencialismo, paternalismo, clientelismo e subordinação da população em detrimento da cidadania.

Devido a essa estrutura herdada do caráter patrimonialista do Estado brasileiro, o Brasil assiste dificuldades em construir seu espaço público devido à sua privatização por grupos oligárquicos que sempre se fizeram presentes no Estado. Quando as políticas estão voltadas para uma só classe, ou quando o Estado está subordinado a esse grupo, o que deveria ser de domínio público, acaba sendo privatizado. As instituições, os governos e as políticas ficam subordinados ao poder financeiro desses grupos, assim como as comunidades locais, que também ficam à mercê destes interesses (Paiva, 2001; Schmidt, 2006).

Dentro desse contexto, construir um espaço público, com políticas que priorizassem as minorias, o combate à pobreza e, por consequência, venha a ser de inclusão social, é tarefa difícil. Pois tanto o espaço público encontra-se privatizado, como a sociedade civil é enfraquecida e desorganizada. A baixa credibilidade do Estado, segundo Lima (2006), gera um baixo comprometimento da sociedade civil nas questões sociais, que, aliado à interferência da política partidária e a falta de capital social, criam fragilidades no processo. Mesmo quando o país adotou políticas voltadas para o desenvolvimento industrial e abriu as portas para o capital internacional, o mercado interno não obteve êxito em termos de desenvolvimento, devido o domínio das políticas tradicionais.

Saliente-se aqui a necessária separação entre crescimento econômico e desenvolvimento, como observado por Machado e Vieira (2016). O crescimento econômico para ser configurado como desenvolvimento é preciso considerar as condições de vida da população. Quando se trata de crescimento econômico deve-se ter em mente que ele é um elemento quantitativo, enquanto que o desenvolvimento é posto como um crescimento qualitativo e em favor da efetivação da cidadania.

No Brasil, na década de 1970, as políticas públicas eram voltadas para as questões sociais, entretanto eram estimuladas por interferências de movimentos internacionais, visando a mudanças numa cultura que agora seria baseada na participação e envolvimento social, pois, segundo Lima (2006), quando se adotam estratégias de mobilização, sensibilização, capacitação e acompanhamento podem-se mudar os paradigmas, abandonando a velha política, concentrada nas mãos das elites, para políticas mais inclusivas e voltadas para as questões sociais e comunitárias.

Outro aspecto que foi introduzido na década acima posta foi o desenvolvimento sustentável, que a partir da Conferência de Estocolmo em 1972 e com a crise do petróleo em 1973, que gerou o desaceleramento do crescimento econômico, e a percepção de que os recursos naturais eram finitos, o modelo de desenvolvimento adotado caiu em crise, pois foi colocada à prova a sua efetividade. Sabe-se que este modelo fordista está fadado a extinção, pois compromete o meio ambiente, esgota os recursos naturais onde é aplicado e não possui visão em longo prazo em termos econômicos, sociais e ambientais comprometendo, assim, o desenvolvimento das atuais e futuras gerações. Desta forma, não basta apenas pensar em um desenvolvimento, mas esse precisa ser obrigatoriamente sustentável (Buarque, 2008). A Constituição Federal brasileira, promulgada em 1988 (Brasil, 1988), reforça as concepções de âmbito internacional e 
inaugura um novo paradigma nas políticas públicas, que passam a ter caráter mais social, atribuindo importantes objetivos fundamentais à Nação:

Art. $3^{\circ}$ Constituem objetivos fundamentais da República Federativa do Brasil:

I - construir uma sociedade livre, justa e solidária;

II - garantir o desenvolvimento nacional;

II - erradicar a pobreza e a marginalização e reduzir as desigualdades sociais e regionais;

IV - promover o bem de todos, sem preconceitos de origem, raça, sexo, cor, idade e quaisquer outras formas de discriminação. (Brasil, 1988)

Como afirmam Souza (2006) e Ferranini (2012), a nova constituição alicerça os fundamentos legais e éticopolíticos na democratização e na universalização dos direitos sociais. Desta forma, o Estado assume legalmente, e de forma mais ampla, sua responsabilidade social, absorvendo uma amplitude de responsabilidades, que só podem ser atingidas mediante políticas públicas de educação, saúde, meio ambiente, transporte, acessibilidade e mobilidade amplas e democráticas. Assim como termina por efetivar os pilares da sustentabilidade no ordenamento jurídico brasileiro, ao reservar um capítulo especial às questões ambientais:

Art. 225. Todos têm direito ao meio ambiente ecologicamente equilibrado, bem de uso comum do povo e essencial à sadia qualidade de vida, impondo-se ao Poder Público e à coletividade o dever de defendê-lo e preservá-lo para as presentes e futuras gerações.

$\S 1^{\circ}$ Para assegurar a efetividade desse direito, incumbe ao Poder Público:

I - preservar e restaurar os processos ecológicos essenciais e prover o manejo ecológico das espécies e ecossistemas;

II - preservar a diversidade e a integridade do patrimônio genético do País e fiscalizar as entidades dedicadas à pesquisa e manipulação de material genético;
III - definir, em todas as unidades da Federação, espaços territoriais e seus componentes a serem especialmente protegidos, sendo a alteração e a supressão permitidas somente através de lei, vedada qualquer utilização que comprometa a integridade dos atributos que justifiquem sua proteção;

IV - exigir, na forma da lei, para instalação de obra ou atividade potencialmente causadora de significativa degradação do meio ambiente, estudo prévio de impacto ambiental, a que se dará publicidade;

V - controlar a produção, a comercialização e o emprego de técnicas, métodos e substâncias que comportem risco para a vida, a qualidade de vida e o meio ambiente;

VI - promover a educação ambiental em todos os níveis de ensino e a conscientização pública para a preservação do meio ambiente;

VII - proteger a fauna e a flora, vedadas, na forma da lei, as práticas que coloquem em risco sua função ecológica, provoquem a extinção de espécies ou submetam os animais a crueldade.

$\S 2^{\circ}$ Aquele que explorar recursos minerais fica obrigado a recuperar o meio ambiente degradado, de acordo com solução técnica exigida pelo órgão público competente, na forma da lei.

$\S 3^{\circ}$ As condutas e atividades consideradas lesivas ao meio ambiente sujeitarão os infratores, pessoas físicas ou jurídicas, a sanções penais e administrativas, independentemente da obrigação de reparar os danos causados.

$\S 4^{\circ}$ A Floresta Amazônica brasileira, a Mata Atlântica, a Serra do Mar, o Pantanal Mato-Grossense e a Zona Costeira são patrimônio nacional, e sua utilização far-se-á, na forma da lei, dentro de condições que assegurem a preservação do meio ambiente, inclusive quanto ao uso dos recursos naturais.

$\S 5^{\circ}$ São indisponíveis as terras devolutas ou arrecadadas pelos Estados, por ações discriminatórias, necessárias à proteção dos ecossistemas naturais.

$\S 6^{\circ}$ As usinas que operem com reator nuclear deverão ter sua localização 
definida em lei federal, sem o que não poderão ser instaladas.

$\S 7^{\circ}$ Para fins do disposto na parte final do inciso VII do $\S 1^{\circ}$ deste artigo, não se consideram cruéis as práticas desportivas que utilizem animais, desde que sejam manifestações culturais, conforme o $\S 1^{\circ}$ do art. 215 desta Constituição Federal, registradas como bem de natureza imaterial integrante do patrimônio cultural brasileiro, devendo ser regulamentadas por lei específica que assegure o bem-estar dos animais envolvidos. (Incluído pela Emenda Constitucional $n^{\circ}$ 96, de 2017) (Brasil, 1988).

Mas a conquista das proteções ao meio ambiente contidas na Constituição de 1988 e repercutidas nas legislações federais, estaduais e municipais não foi possível sem as pressões internacionais. De acordo com Camara (2013),

[...] a evolução da política ambiental brasileira é um reflexo da evolução das políticas públicas no contexto internacional, da adoção dos princípios da descentralização, da desestatização, da participação social e da institucionalização de processos gerenciais integrados e dinâmicos. Tais mudanças se dão, principalmente, a partir da percepção da falência dos atuais modelos de desenvolvimento e suas influências negativas na sociedade, na economia e no meio ambiente, resultando em transformações de paradigmas de políticas e de instituições públicas, sociais e privadas e suas interrelações no uso dos recursos ambientais, na apropriação dos territórios e nos modelos de gestão adotados (Camara, 2013, p. 126).

É dentro desta nova perspectiva que o desenvolvimento local passa a ser considerado, pois, como explica Jacobi (2002), o desenvolvimento local surge como cenário de efetivação de uma prática favorável à atuação protagonizada pelos agentes sociais, através da transferência da autoridade centralizadora para autoridade legal e política local. É uma busca pela articulação entre os agentes, considerando seus interes- ses e prerrogativas, como bem resume Somekh (2002):

Queremos um desenvolvimento local com inclusão social, em que haja cooperação, criação e alargamento de esferas públicas, em que diferentes atores políticos, econômicos, sociais dialoguem de maneira transparente a partir de seus próprios interesses em conflito, buscando construir um novo desenvolvimento local em conjunto (Somekh, 2002, p. 33).

O local então é determinado, segundo a concepção de Ferrarini (2012) como o espaço de possibilidades das criações e soluções que não podem ser conseguidas na totalidade. Pois, ninguém melhor para criar oportunidades, saber os problemas e propor soluções do que a comunidade local e seus diversos atores empresas, associações, instituições públicas, etc. - através da cooperação e transparência no alcance dos diversos interesses.

Desta forma, é necessário priorizar os agentes locais através do desenvolvimento do capital social. Capital social pode ser entendido como um conjunto de bens sociais psicológicos, cognitivos e institucionais, que estão relacionados a um ator ou grupo, que através desse conjunto possuem habilidades para estabelecer redes de relações sociais, possibilitando uma cooperação benéfica, para o próprio indivíduo e para o grupo (Coleman, 1990; Portes, 1998).

Além disto, o engajamento da sociedade civil, a partir de indivíduos com quantidade e qualidade de capital social evitam as ações oportunistas associadas às políticas partidárias e aos grupos dominantes. Desta forma, se passa a construir um espaço que é público e democrático, mas que não exclui a presença da iniciativa privada, mas que busca um movimento sinérgico entre os diversos atores. Tomando por base o que Buarque (2008) explica, seria uma mudança de paradigma de antigas concepções para novas visões, holísticas, sobre o papel dos diversos atores sociais. Para o autor coloca a sustentabilidade não como uma opção, mas como o único caminho viável para a sociedade moderna. 
Dentro desta nova perspectiva de desenvolvimento, Ferrarini (2012) utiliza a definição de política emancipatória, que seria mudar do modelo do "fazer caridade", para uma política que crie oportunidades e perspectivas para que a população da localidade consiga se desenvolver através de seus próprios meios e potencialidades. Essas oportunidades criadas pelo Estado são obtidas mediante a posse de ativos como educação, crédito, reforma agrária etc. A partir da apropriação adequada desses ativos, a população local teria condições de se desenvolver de maneira independente, não ficando refém da caridade do Estado ou de grupos dominantes.

Como exemplo destas novas políticas, podem-se citar algumas de iniciativa pública e privada que já utilizam o conceito de desenvolvimento local sustentável. Como exemplo, a Política Nacional de Recursos Hídricos, que, através da instituição dos comitês de bacias hidrográficas abrem espaço para a gestão democrática com a participação dos diversos atores, ou a obrigação de realizar audiências públicas antes da implantação de meios econômicos para que a sociedade seja ouvida e avisada dos danos ambientais que poderão ser ocasionados; projetos que são financiados por empresas privadas (Kemerich et al., 2014), e a Fundação o Boticário, que apoia programas e projetos para a conservação das unidades de conservação (Grupo Boticário, 2016).

Diante do exposto, o Brasil precisa investir cada vez mais em políticas públicas que possibilitem a inserção da sociedade civil organizada e mobilizada na busca do desenvolvimento de suas localidades e que seja capaz de tomar decisões de cunho coletivo, mais solidárias e éticas, a fim de beneficiar toda a comunidade. Mudando os paradigmas atuais, através da extinção de políticas elitizadas, partidárias e centralizadoras, para o desenvolvimento do capital social local e das potencialidades locais, através de práticas sustentáveis.

É necessário, portanto, aprofundar as discussões em torno da importância do capital social nesse novo paradigma de desenvolvimento e, ainda, para o que seria efetivamente o desenvolvimento local sustentável.

\section{A importância do capital social para o desenvolvimento local}

O desenvolvimento durante muito tempo ficou atrelado ao crescimento econômico no âmbito global, restrito exclusivamente ao sistema de mercado, e aos modelos tradicionais de crescimento, que consideravam apenas as variáveis econômicas, o capital físico e tecnológico como determinantes do processo econômico de crescimento. Sendo esse fator essencial, porém, não suficiente para ensejar a qualidade de vida das populações e o desenvolvimento local, tendo a necessidade de um contexto que envolve variáveis que não podem ser ignoradas ao processo como: fatores culturais, econômicos, políticos e ambientais.

A partir dos anos 1990, o conhecimento sobre o desenvolvimento e a prática de projetos de desenvolvimento local passou por profunda transformação: o universalismo do desenvolvimento é seriamente questionado, onde, as marcas da desigualdade social e econômica ocuparam o centro das atenções das correntes dominantes da teoria do desenvolvimento. Autores como Wolfgang Sachs, Serge Latouche, Ivan Lllich e Arundathy Roy sustentam que é fundamental requalificar e analisar criticamente os processos de transformação social compreendidos sob a etiqueta do desenvolvimento.

Os estudos sobre desenvolvimento evidenciam a relevância da participação das comunidades, ou seja, da atuação dos indivíduos como sujeitos ativos e envolvidos na busca de melhorias e transformações positivas no local onde vivem. Levantando esta questão, Helpman (2004) faz ver que existem outros fatores determinantes do desenvolvimento, porque acontece que algumas áreas apresentam desenvolvimento mais rápido que outras, com padrões de infraestrutura, crescimento e comportamento social diferentes, colocando em prova o modelo tradicional de desenvolvimento. 
Surgem nesse contexto, novos temas como descentralização, a governança local, a participação, a emergência da sociedade civil e mais recentemente o termo capital social, que integram os novos projetos para o desenvolvimento social. Ainda que tenham naturezas distintas, todos esses novos termos têm relação direta com aspectos institucionais, políticos, culturais e sociais da estruturação de uma política voltada ao desenvolvimento. Necessário, então, por em evidência a diversidade e a particularidade dos contextos locais. Tal análise endógena e particular faz perceber que o local é construído por interações sociais, culturais, econômicas, políticas e ambientais que alicerçam o desenvolvimento.

O tema capital social recebe destaque, recebendo considerável atenção, particularmente entre sociólogos, economistas e cientistas políticos, além de organizações públicas e privadas. Essa temática é categorizada como uma instituição de valores, normas, confiança, que sustenta a cooperação nos grupos ou entre os grupos sociais (Putnam, 1996). Putnam (1996) define o capital social como a atuação de comunidades no desenvolvimento e melhorias da própria comunidade, de forma que a organização se expresse através das redes sociais.

Desde então, o capital social se tornou uma variável relevante com enfoque na liberdade da participação da sociedade civil no processo de desenvolvimento, transformando-se num importante instrumento no processo de desenvolvimento territorial. Robinson (2002) define o capital social enquanto "um conjunto de recursos a que um indivíduo ou um grupo tem acesso em função do fato de pertencer a uma rede de intercâmbio e relações mutuamente proveitosas” (Robinson, 2002, p. 3).

O capital social seria, assim, um estoque de relações e valores e seu aumento dependeria do aprofundamento destas relações e cooperação entre esses atores locais, de sua multiplicação, intensidade, reatualização e criação de redes de relações. Essa interação comunitária resulta em oportunidades de crescimento, melhorias, mudanças e intervenções na sociedade na qual os indivíduos estariam envolvidos, propiciando o desenvolvimento local.

É possível traçar três principais conceitos de capital social (Schuller et al., 2000). A primeira limita-se aos escritos por autores, provenientes das ciências sociais, que difundiram expressivamente o termo, destacando-se Pierre Bourdieu, James Coleman e Robert Putnam. A segunda fase trata de elementos chave como confiança, coesão social, redes e normas institucionais, em vários contextos de disciplinas em que o conceito tem sido usado implícito e explicitamente. O terceiro, e mais extenso, inclui autores cuja produção contém elementos precursores do conceito social relacionado à sociologia clássica do século XIX, incluindo outros, como Emile Durkheim e Max Weber. De acordo com Sen (2000),

[...] a construção do desenvolvimento está relacionada à liberdade das pessoas de produzir e reproduzir sua existência, de forma que os sujeitos possam estar ativamente envolvidos, por isso, é importante evidenciar que cada vez mais as redes sociais passaram a ganhar mais legitimidade e atrair os olhares de diversos setores da sociedade, sendo uma forma de organização e desempenho do capital social (Sen, 2000, p. 138).

Em outro sentido surgem várias razões para o conceito de capital social ser difundido tão rapidamente, entre elas, a valorização das relações e estruturas sociais no discurso político e na ótica econômica, o reconhecimento dos recursos embutidos em estruturas e redes sociais não contabilizados por outras formas de capital, e a valorização de sua importância para o desempenho econômico; a necessidade de desenvolver conceitos que reflitam a complexidade e o inter-relacionamento das várias esferas de intervenção humana; seu potencial de alavancagem política. Putnam (2000) define capital social como um sistema democrático, que leva a uma ação coletiva orientada para o bem-estar.

Putnam (2000) associa o capital social como algo positivo, onde a sua existência está associado à moral entre 
capital social e objetivo socialmente desejado, para o autor capital é sinônimo de civismo, onde sua existência acarreta resultados benéficos e positivos para a coletividade. Desta forma o

\begin{abstract}
[...] capital social é um conceito que se insere dentro da concepção teórica da cultura política e considera as características culturais, de existência de confiança, reciprocidade e solidariedade na sociedade civil, vitais para o aperfeiçoamento da democracia, das comunidades, das pessoas e, inclusive da sociedade política, o Estado (Putnam e Goss, 2002, p. 89).
\end{abstract}

Sendo o capital social uma estratégia de desenvolvimento, que proporciona o engajamento das sociedades em redes, ele auxilia na articulação de umdanças significativas, na elevação do capital social e no empoderamento. O Capital Social possui então, uma estrutura multidimensional. Existem evidências de que ele pode ser usado para promover a redução da pobreza, o desenvolvimento e o bem-estar social, o que aproxima os interesses da sociologia e da economia nesse campo, sendo uma forma de relações sociais existentes nas comunidades. Por este ângulo Moraes (2003) expõe que

[...] de acordo com os diversos autores que tratam do tema, a noção de capital social configura um promissor e emergente modelo teórico que pode transformar-se num importante instrumento para o estudo de como se forma o processo de desenvolvimento territorial. No entanto, são necessários ainda mais estudos empíricos que mostrem a relação efetiva entre 0 capital social e o desenvolvimento territorial e avaliem os propósitos e as potencialidades das políticas públicas na indução e formação de capital social” (Moraes, 2003, p. 146).

Moraes (2003) enfatiza a pertinência e importância do conceito de capital social como um "novo paradigma" de desenvolvimento. Sendo este, determinante, para o processo de crescimento/desenvolvimento dos países, ou das regiões, ou de comunidades locais. Onde as relações entre esses atores sociais provocam mudanças, promovem melhorias, bem-estar e oportunidades sociais adequadas àquela localidade, o que concomitantemente viabiliza a competitividade e o desenvolvimento econômico local.

O termo capital social trata-se de um bem capaz de multiplicar-se cumulativamente e gerar outros bens, é capaz de gerar lucros da mesma forma que os demais tipos de capital. Grootaert e Bastelaer (2001) colocam esta questão da seguinte forma: o principal atributo do capital é que este é um patrimônio acumulado que gera um fluxo de benefícios.

Nestes termos, trata-se de verificar se o capital social será, assim como um ativo, capaz de gerar uma cadeia de benefícios.

De qualquer forma não existe, proposta e aceite, uma medida única para o capital social. Entre as razões apontadas, destacam-se a multiplicidade de significados do termo, o fato da natureza e da forma do capital social mudar com o tempo, na medida em que variam os elos formais e informais, e, finalmente, $\mathrm{o}$ fato de os estudos ainda estarem em desenvolvimento, por se trata de um termo ainda não inteiramente maduro, apesar do seu tempo de existência (Woolcock e Narayan, 2002).

Capital social pode ser entendido dentro desse contexto, como o somatório de valores culturais, políticos, econômicos e ambientais de uma determinada comunidade, que existe e cresce a partir de relações de confiança e cooperação, sendo um bem coletivo e compromisso cívico. O Capital Social cultiva os recursos acumulados que podem ser utilizados e mantidos para o futuro, numa construção histórica específica, com particularidades e características próprias.

\section{Desenvolvimento sustentável local}

O conceito de desenvolvimento sustentável surgiu em meados das décadas de 1970 e 1980 como uma ampliação da ideia de desenvolvimento, onde a partir do diálogo do governo, das organizações sociais e/ou sindicais e as organizações 
empresarias buscavam consenso sobre de como deveria ocorrer o desenvolvimento (Lacerda, 2017). Uma noção amplamente adotada pelos países membro das Organizações das Nações Unidas (ONU), orientadora de práticas e investimentos em crescimento econômico, políticas de produção e mercado nos países considerados tanto "desenvolvidos" quanto "subdesenvolvidos”.

Donaire (1999) explica o desenvolvimento sustentável como um conjunto de ações do presente que busca garantir a sobrevivência e a possibilidade de saciar as necessidades das gerações futuras.

O fato é que, "Desenvolvimento sustentável” tem se tornado um conceito muito popular, especialmente a partir do relatório da Comissão Brundtland, de 1987 (CMMAD, 1991). Muitos o consideram uma grande panaceia, a mudança crucial que precisamos fazer se quisermos um mundo melhor e um futuro com uma qualidade de vida decente para nossos filhos (Fernandez, 2005).

Para Fernandez (2005), desenvolvimento sustentável parece ser o que todos queremos: manter ou aumentar $\mathrm{o}$ alto padrão de vida do Primeiro Mundo e levar o Terceiro Mundo para o mesmo padrão, tudo isso sem comprometer o chamado "meio ambiente" e o futuro de todos nós. No entanto, cabe perguntar: a não ser como ideal, será que desenvolvimento sustentável existe? Ainda segundo Fernandez (2005), na maioria dos casos, os projetos que são ditos sustentáveis, na verdade são apenas ditos como tais, sem ser demonstrados ou nem mesmo testados.

Por outro lado, Daly (2004), afirma que o desenvolvimento sustentável só faz sentido para a economia se compreendido que deverá ocorrer sem o crescimento. Este autor ainda afirma que o desenvolvimento sustentável tem sido tratado como sinônimo para o oximoro crescimento sustentável e que isso não deve acontecer, ele ressalta que dentro do contexto politico é difícil reconhecer que o crescimento deve ser limitado, porém ele é insustentável, devendo ser urgentemente substituído por um desenvolvimento sustentável. De acordo com Sachs (2005), o desenvolvimento, consiste na multiplicação de escolhas não apenas quantitativas, mas também qualitativas, escapando do reducionismo economicista e da definição de crescimento econômico.

Nesta perspectiva, surgem questionamentos profundos a respeito do caminho a seguir pela humanidade na tentativa de preservar a própria vida sobre o planeta. Como falar em crescer de forma sustentável quando a atual escala da economia mostra a insustentabilidade de forma evidente e definitiva? Até quanto a economia pode crescer? Ao colorirmos o crescimento de verde, conseguiremos anular ou retardar a insustentabilidade do modelo? Diante destes questionamentos ancoramos nosso raciocínio no exposto por Furtado (1974) ao afirmar de que só haverá verdadeiro desenvolvimento, se este estiver aliado a algum projeto social e que esse não deve confundir com crescimento econômico (Furtado, 1974).

Todavia, apesar das discussões sobre o que seria esse desenvolvimento sustentável ou se ele poderá ser alcançado, o ambiente globalizado, as percepções dos desastres ambientais e das brechas deixadas pela ciência e pela tecnologia, abre-se espaço, no cenário atual, para mudanças de paradigmas e novos conceitos, que ganham a cada dia mais adesão por parte das pessoas.

Neste quadro de grandes mudanças, o conceito de desenvolvimento local sustentável surge para mais uma mudança de paradigma. Segundo Buarque (2008), desenvolvimento local sustentável é um processo de mudança, de dinamismo econômico que busca a melhoria da qualidade de vida de pequenas localidades. De acordo com o autor é necessário elevar as potencialidades e a qualidade de vida dessas populações, lhes dando independência para sobreviverem, ao mesmo tempo em que possam preservar seus recursos.

Para que isso seja possível é necessária uma organização da sociedade civil que precisa construir capital social em quantidade e qualidade elevados. Pois segundo Buarque, o desenvolvimento vai depender diretamente da capacidade dos atores sociais se organizarem e se mobi- 
liarem. É o que defende Dowbor (2006) quando afirma que o desenvolvimento local é voltado para as necessidades das pessoas e do seu ambiente e não apenas para os lucros, que apesar de importantes, não devem ser o único objetivo, pois nem sempre o ganho de capital é revertido em qualidade de vida.

Todavia, para que se possa alcançar um desenvolvimento sustentável local, que consiga desenvolver a economia local aliando ao desenvolvimento social, precisase de um ambiente político favorável a tais perspectivas e principalmente investimentos em capacitação humana (educação) para que se possa romper com as antigas concepções, que se baseiam basicamente em esperar passivamente as iniciativas dos governos ou das grandes empresas (Buarque, 2008).

Dentro desse contexto, a educação é fator preponderante para o desenvolvimento, pois contribui para conscientizar as pessoas, para organiza-las em prol de objetivo coletivos, além de contribuir para aumentar a autoconfiança e autoestima, tão necessários às comunidades de pequenas localidades. Isto, aliado à concepção de valores éticos e morais fortes, diminuem a possibilidade da geração atual privar de forma cruel as próximas gerações de herdarem um planeta habitável (Sachs, 2005).

Para o Brasil, país de dimensões continentais e que como demonstrado anteriormente, demorou e ainda luta para construir seu espaço interno, a perspectiva do desenvolvimento local sustentável é atrativa e se põe como uma alternativa para melhorar a distribuição de renda e a qualidade de vida das pessoas. Pois promove mudanças significativas nos padrões de consumo, na distribuição de renda, na inserção social e no tratamento com os trabalhadores, além de promover mudanças nas políticas públicas.

Ainda trilhando o caminho do desenvolvimento, o país não pode abandonar o crescimento que gere emprego e renda, todavia segundo Buarque (2008) o desenvolvimento sustentável é uma exigência do milênio e as práticas anteriormente apoiadas - crescimento a qualquer custo - perderam adesão. Agora não basta mais para as pessoas um crescimento econômico desigual, péssimas condições de trabalho; estimasse por uma boa qualidade de vida, pela dignidade, pela preservação dos recursos naturais e pela distribuição das riquezas (Buarque, 2008).

Por fim, o desenvolvimento local sustentável busca atingir um desenvolvimento local, que se integre aos mercados globalizados, com espaço para que as potencialidades locais sejam competitivas, sem abrir mão da preservação de seus recursos. Isso só poderá ser alcançado através da organização da sociedade civil e da valorização da educação, possibilitando a essas comunidades desenvolver uma alta qualidade de capital social, em um ambiente que favoreça a participação das pessoas e com leis e políticas que legitimem e estimulem essa participação.

\section{Considerações finais}

Ao término do presente construto teórico pode-se perceber a necessidade da sociedade moderna na busca de um desenvolvimento que garanta o desenvolvimento social e econômico, mas que utilize os recursos naturais de forma eficiente e responsável. É uma mudança de paradigma, do crescimento econômico, onde se visualiza apenas o lucro, para o desenvolvimento sustentável que busca desenvolver a vertente econômica, social e ambiental. No que se refere ao desenvolvimento local sustentável, as discussões apontam para a necessidade de se olhar para as pequenas comunidades, em um mundo globalizado, levando em consideração suas necessidades e suas contribuições para o desenvolvimento global. No que concerne ao Brasil, pais de dimensões continentais, o desenvolvimento das pequenas comunidades, através de políticas participativas e de estimulo ao desenvolvimento das potencialidades locais, auxilia no desenvolvimento social e econômico, pois perpassa as políticas de assistencialismo, para dá autonomia na busca de melhorias na qualidade de vida.

$\mathrm{Na}$ construção desse desenvolvimento local sustentável o capital social é variável determinante, pois a sua qualidade 
e quantidade, quando presente nesses ambientes, favorecem a formação de redes entre os indivíduos fazendo com que possam se organizar e se mobilizar em busca de seus interesses, legitimando suas ações. Essas redes são construídas com ética e valores morais, diminuindo assim as ações oportunistas e as manipulações das políticas partidárias. Desta forma, o capital social é um bem da comunidade, um somatório de variáveis culturais, econômicas e política da vida social de uma população. Sendo um bem coletivo que garante o respeito às normas de confiança mútua, onde os bens desenvolvidos neste processo são compartilhados no nível de um grupo e sociedade.

\section{Referências}

Brasil. Constituição da República Federativa do Brasil de 1988. Disponível em: $<$ http://www.planalto.gov.br/ccivil_03/constitui cao/constituicao.htm>. Acesso em: 26 ago. 2016.

Buarque, S. C. Construindo o desenvolvimento local sustentável. 4. ed. Rio de Janeiro: Garamond, 2008.

Camara, J. B. D. Governança ambiental no Brasil: ecos do passado. Revista de Sociologia e Política, v. 21, n. 46, p. 125-146, 2013. https://doi.org/10.1590/S0104-44782013000200 008

CMMAD - Comissão Mundial sobre o Meio Ambiente e Desenvolvimento. Nosso futuro Comum. 2. ed. Rio de Janeiro: Editora da FGV, 1991.

Coleman, J. S. Foundations of social theory. London: Harvard University Press, 1990.

Daly, H. E. Crescimento sustentável? Não, obrigado. Ambiente \& Sociedade, v. 7, n. 2, p. 197-201, 2004. https://doi.org/10.1590/ S1414-753X2004000200012

Donaire, D. Gestão ambiental na empresa. 2. ed. São Paulo: Atlas, 1999.

Dowbor, L. Cidadania e desenvolvimento local: negociando o conceito de desenvolvimento local. Anais do X Colóquio de Poder Local, Salvador, 2006.

Fernandez, F. Aprendendo a lição de Chaco Canyon: do "desenvolvimento sustentável" a uma vida sustentável. São Paulo: Ethos, 2005.

Ferrarini, A. V. Desenvolvimento local integrado e sustentável: uma metodologia para políticas e programas de superação da pobreza. Interações, v. 13， n. 2, p. 233-241， 2012. https://doi.org/10.1590/S1518-70122012000200 010

Fonseca, I. F.; Bursztyn, M. A banalização da sustentabilidade: reflexões sobre governança ambiental em escala local. Sociedade e Estado, v. 24, n. 1, p. 17-46, 2009. https://doi.org/ 10.1590/S0102-69922009000100003

Furtado, C. O mito do desenvolvimento econômico. Rio de Janeiro: Paz e Terra, 1974.

Grootaert, C.; Bastelaer, T. Understanding and measuring social capital: a synthesis of findings and recommendations from the social capital initiative. Washington: World Bank, 2001. (Social Capital Initiative Working Paper, 24). Disponível em: <http://siteresources. worldbank.org/INTSOCIALCAPITAL/Resourc es/Social-Capital-Initiative-Working-Paper-

Series/SCI-WPS-24.pdf>. Acesso em: 26 ago. 2016.

Grupo Boticário. Relatório de sustentabilidade do Grupo Boticário 2015. São Paulo: Grupo Boticário, 2016. Disponível em: $<$ http://relatoweb.com.br/boticario/15/files/Relat orio-de-sustentabilidade-2015.pdf $>$. Acesso em: 26 ago. 2016.

Helpman, E. The mystery of economic growth. Cambridge: The Belknap Press of Harvard, 2004.

Jacobi, P. R. Políticas sociais e ampliação da cidadania. 2. ed. Rio de Janeiro: Editora FGV, 2002.

Kemerich, P. D. C.; Ritter, L. G.; Dulac, V. F. Gerenciamento de comitês de bacia: desafios e potencialidades. Revista Monografias Ambientais, v. 13, n. 5, p. 3737-3743, 2014. https://doi.org/10.5902/2236130814412

Lacerda, A. V. Sustentabilidade: um olhar sobre a relação homem natureza. Revista Brasileira de Gestão Ambiental e Sustententabilidade, $\begin{array}{llll}\text { v. } 4, & \text { n. } 7, & \text { p. 15-19, }\end{array}$ https://doi.org/10.21438/rbgas.040702

Lima, G. F. Crise ambiental, educação e cidadania: os desafios da sustentabilidade emancipatória. In: Loureiro, F.; Layargues, P.; Castro, R. (Orgs.). Educação ambiental: repensando o espaço da cidadania. São Paulo: Cortez, 2002.

Machado, B. B.; Vieira, E. T. Aspectos do crescimento econômico e do desenvolvimento humano no município de jambeiro na década de 2000. Revista Competitividade e Sustentabilidade, v. 3, n. 2, p. 1-13, 2016. https://doi.org/10.5935/2359-5876.20160008 
Moraes, J. L. A. Capital social e desenvolvimento regional. In: Correa, S. M. S. (Org.). Capital social e desenvolvimento regional. Santa Cruz do Sul: Edunisc, 2003.

Novaes, R. C. Investimento em capital social: como estratégia para a construção da sustentabilidade local - apontamentos teóricos metodológicos. Rio de Janeiro: Engema, 2005.

Paiva, A. R. O público, o privado e a cidadania possível: a construção do espaço públicos brasileiro. Rio de Janeiro: Ed. Senac, 2001.

Portes, A. Social capital: its origins and applications in modern sociology. Annual Review of Sociology, v. 24, p. 1-24, 1998. https://doi.org/10.1146/annurev.soc.24.1.1

Putnam, R. Bowling alone. Nova Iorque: Simon and Schuster, 2000.

Putnam, R. D. Comunidade e democracia: a experiência da Itália moderna. Rio de Janeiro: Editora FGV, 1996.

Putnam, R.; Goss, K. Introduction. In: Putnam, R. Democracies in flux: the evolution of social capital in contemporary societies. Nova Iorque: Oxford University Press, 2002. p. 3-21.

Robinson, D. (Org.). Building social capital. Wellington, Nova Zelândia: Institute of Policy Studies, Victoria University of Wellington, 2002.

Romeiro, A. R. Sustainable development: an ecological economics perspective. Estudos Avançados, v. 26, n. 74, p. 65-92, 2012. http://doi.org/10.1590/S0103-40142012000100 006
Sachs, I. Desenvolvimento includente, sustentável, sustentado. Rio de Janeiro: Garamond, 2005.

Schmidt, M. F. Nova História crítica. São Paulo: Nova Geração, 2006.

Schuller, T.; Baron, S.; Field, J. Social capital: a review and critique. In: Baron, S.; Field, J.; Schuller, T. (Eds.). Social capital: critical perspectives. Oxford: Oxford University Press, 2000.

Sen, A. K. Desenvolvimento com liberdade. São Paulo: Companhia das Letras, 2000.

Somekh, N. A construção social da cidade: desenvolvimento local e projetos urbanos. In: Dowbor, L.; Pochmann M. (Orgs.). Políticas para o desenvolvimento local. São Paulo: Fundação Perseu Abramo, 2008. p. 17-40.

Souza, C. Políticas públicas: uma revisão da literatura. Sociologias, v. 8, n. 16, p. 20-45, $2006 . \quad$ https://doi.org/10.1590/S151745222006000200003

Woolcock, M.; Narayan, D. Social capital: implications for development theory, research, and policy. World Bank Research Observer, $\begin{array}{llll}\text { v. } 15, & \text { n. } 2, \quad \text { p. 225-250, } & 2000 .\end{array}$ https://doi.org/10.1093/wbro/15.2.225 